\title{
RAPID RESPONSE TOOLS AND DATASETS FOR POST-FIRE EROSION MODELING: LINKING REMOTE SENSING AND PROCESS-BASED HYDROLOGICAL MODELS TO SUPPORT POST-FIRE REMEDIATION
}

\author{
M. E. Miller ${ }^{\text {a, } * \text { W. J. Elliot }}{ }^{\mathrm{b}}$, K. A. Endsley ${ }^{\mathrm{a}}$, P. R. Robichaud ${ }^{\mathrm{b}}$, M. Billmire ${ }^{\mathrm{a}}$ \\ ${ }^{a}$ Michigan Tech Research Institute, Michigan Tech, 3600 Green Court, Suite 100, Ann Arbor, MI, USA 48105 - (memiller, \\ kaendsle, mgbillmi)@mtu.edu \\ ${ }^{\mathrm{b}}$ USDA Forest Service Rocky Mountain Research Station Forestry Sciences Laboratory, Moscow, ID, USA - (welliot, \\ probichaud)@fs.fed.us
}

KEY WORDS: Forestry, Hydrology, Hazards, Forest fire, Databases, Soil, Land Cover

\begin{abstract}
:
Post-fire flooding and erosion can pose a serious threat to life, property, and municipal water supplies. Increased peak flows and sediment delivery due to the loss of surface cover and fire-induced changes in soil properties are of great concern to both resource managers and the public. To respond to this threat, interdisciplinary Burned Area Emergency Response (BAER) Teams are formed to assess potential erosion and flood risks. These teams are under tight deadlines as remediation plans and treatments must be developed and implemented before the first major storms in order to be effective. One of the primary sources of information for making these decisions is a burn severity map derived from remote sensing data (typically Landsat) that reflects fire induced changes in vegetative cover and soil properties. Slope, soils, land cover, and climate are also important parameters that need to be considered when accessing risk. Many modeling tools and datasets have been developed to assist BAER teams, but process-based and spatially explicit empirical models are currently under-utilized compared to simpler, lumped models because they are both more difficult to set up and require spatially explicit inputs such as digital elevation models, soils, and land cover. We are working to facilitate the use of models by preparing spatial datasets within a web-based tool that rapidly modifies model inputs using burn severity maps derived from earth observation data. Automating the creation of model inputs facilitates the wider use of more accurate, process-based models for spatially explicit predictions of post-fire erosion and runoff.
\end{abstract}

\section{INTRODUCTION}

Being prepared for an emergency situation is important. Forest and rangeland wildfires not only cause emergency situations while the fire is active, but can also cause emergencies in the year or two following a wildfire. Once the danger of an active wildfire has passed, land managers must rapidly assess the threat from erosion, now heightened due to the loss of vegetation and litter layers from the forest floor and changes in soil properties. Forests are highly valued as protectors of watersheds and reservoirs because the canopy and surface cover protect forest soils from erosion (Robichaud 2000; Moody and Martin 2001). After a wildfire post-fire flooding and erosion can threaten lives, property and water supplies. Flooding after the Buffalo Creek Fire in Colorado resulted in the deaths of two people and sediment from this fire reduced Denver's municipal reservoir capacity by roughly a third (Agnew et al. 1997). Similar losses of life and/or damage to property were reported from floods near Colorado Springs following the 2012 Waldo Canyon Fire and in Boulder, CO following the 2010 Four Mile Canyon Fire. Similar problems are faced downstream of many other fires throughout the western U.S., Canada, and Australia.

The hazards of flooding due to increased runoff and debrisfilled flows are of special concern near the wildland urban interface, cultural sites, municipal water source areas, and sensitive habitats (Robichaud and Brown 2000; Moody and Martin 2001, Cannon et al. 2010). Planning the mitigation of these threats is undertaken by interdisciplinary BAER Teams who work diligently to estimate erosion and flood risk in order to prioritize treatments to protect watersheds and downstream values at risk including life and property (Parsons et al. 2010).
BAER teams must quickly assess the burn scar by mapping out the areas of high, moderate, and low severity in order to prioritize treatment areas. Slope, climate, and location are also important factors in determining risk (Renard et al. 1997; Pietraszek 2006). A severe wildfire can have such a dramatic impact on watersheds that remediation work is often initiated on burned areas before a fire is fully extinguished.

The complexities and uncertainties of erosion processes following wildfires and the high cost of mitigation (up to $\$ 5,000$ per ha) require managers to make tough decisions when it comes to addressing post-fire effects. It is not uncommon for several million dollars to be spent on post-fire mitigation following a wildfire. Earth observations of burn severity are an important component in remediation planning (Parsons et al. 2010), but there are also many modeling tools built to assist land managers (Elliot et al. 2006, 2010 and 2013; Renschler 2003). Spatially explicit and physically based models are currently being under-utilized as they require inputs that depend upon the spatial distribution of burn severity, topography, vegetation and soil. In order to increase the adoption of these models we are building an online database that will provide spatial data and input parameters. The database includes spatial tools to rapidly update input layers with post-fire earth observations of burn severity.

The overall objective of the online database is to provide endusers (BAER Team specialists, land managers and researchers) with the basic tools and spatial data needed to incorporate remotely sensed earth observations into process-based erosion models. End users may select a historical fire or they can upload a new burn severity map into the database. Once

\footnotetext{
* Corresponding author.
} 
uploaded, the burn severity map is combined with vegetation and soils datasets and then delivered to the user pre-formatted for modeling. Improving the accessibility of both modeling capabilities and the required data sets will lead to better assessment tools for forest managers, researchers and BAER Teams.

\subsection{Post-fire Erosion Processes}

Wildfire reduces or totally removes canopy, increasing the exposure of the soil surface to raindrop impact and wind. Normally forest soils are covered with duff (fresh and decomposing leaf litter and organic debris) (Elliot, 2013). The amount of ground cover after burning is a primary control on post-fire erosion rates (Benavides-Solorio and MacDonald 2005) and is an essential input to any post fire erosion model. Wildfire reduces this ground cover, exposing soils to raindrop impact and wind erosion. Raindrop impact can destroy soil aggregation and detach sediment. When combined with shallow overland flow, this shallow runoff can transport fine soil particles and ash to macropores decreasing infiltration rates, and increasing runoff and erosion. The loss of surface cover also increases rill erosion and on steep slopes can aggravate mass failure as surface woody material and below ground root networks no longer stabilize steep slopes (Reid, 2010). The loss of forest vegetation will lead to decreased evapotranspiration, increased soil water content, and decreased root strength, increasing the risk of runoff, flooding and landslides when soils are saturated (Reid, 2010). The hot gases generated by burning duff can coalesce around soil particles, making soils hydrophobic, increasing the risk of high runoff and surface erosion (DeBano, 2000). The heat of the fire can also destroy soil structure, making soil particles more easily detached or erodible.

Upland erosion frequently exceeds the ability of downstream channels to transport the sediment delivered from burned hillslopes, so river valleys and high elevation reservoirs are frequent sites of considerable deposition. Much of the deposited sediment is routed downstream in years following the fire when stream flows are high (Elliot, 2013).

Modeling tools are needed to help prioritize expensive remediation treatments, predict impacts of the treatments in order to justify their costs and to increase understanding of fire effects on watersheds. Several wildfire effects increase the risk of soil erosion from surface water, wind, and mass failure.

\subsection{Earth observations of burn severity}

The sudden changes to a watershed brought about by a large wildfire need to be quantified. Therefore, one of the first and most important priorities of a BAER Team is the development of a burn severity map that reflects fire induced changes in both vegetative cover and soil properties. Currently these maps are known as Burned Area Reflectance Classification (BARC) maps and they are typically generated by the U.S. Department of Agriculture (USDA) Remote Sensing Application Center using multi-spectral earth observation data (Parsons et al. 2010; RSAC, 2011). Many algorithms exist for mapping burn severity, but the most widely accepted algorithm is the differenced Normalized Burn Ratio (NBR) algorithm (Key and Benson, 2006) which has been shown to be well correlated with field measurements of burn severity (Bobbe et al. 2001; Robichaud et al. 2007).
The NBR ratio is:

$\mathrm{NBR}=\left(\mathrm{R}_{\mathrm{NIR}}-\mathrm{R}_{\mathrm{SWIR}}\right) /\left(\mathrm{R}_{\mathrm{NIR}}+\mathrm{R}_{\mathrm{SWIR}}\right)$

where $\quad R_{N I R}=$ satellite reflectance in the near-infrared

$\mathrm{R}_{\mathrm{SWIR}}=$ satellite reflectance in the shortwave-infrared

Next the change in NBR between the pre- and post-fire condition is calculated by:

$\mathrm{dNBR}=\mathrm{NBR}_{\text {prefire }}-\mathrm{NBR}_{\text {postfire }}$

After the fire, reflectance in the NIR band decreases while reflectance in the SWIR band increases. The changes in NBR highlight changes wrought by the fire (Eq. 2). The algorithm assumes the NBR in the unburned areas is unchanged and that climatic and moisture conditions are similar for both the preand post-fire images. The dNBR is strongly positive for firestressed areas and strongly negative for regions experiencing enhanced re-growth due to the fire. Resulting dNBR images are classified into unburned, low, moderate, and high burn severity with varying threshold levels. When possible field measurements of soil burn severity are collected in order to ascertain and verify threshold levels, as they can vary with vegetation (Elliot et al. 2006; Parsons et al., 2011), but this is often not the case. Sometimes the burn severity map is the only estimate of burn severity available. When the BAER Team has time to adjust the BARC map based on soil conditions it then becomes a soil burn severity map (Fig. 1). Ideally, a soil burn severity map is used to create spatial model inputs.

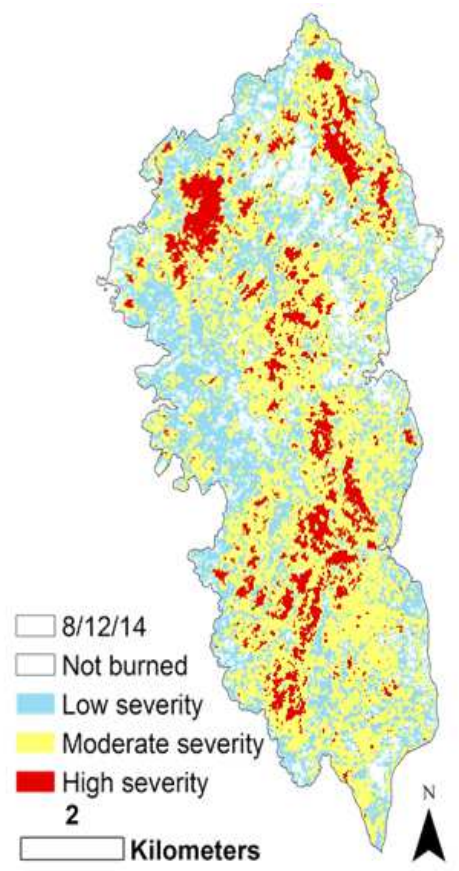

Figure 1. Soil burn severity map of the French Fire in California, the pre-fire image was collected by Landsat 8 on July 26, 2014 and the post-fire image was collected by the Earth Observing-1 Advanced Land Imager on August 9, 2014.

Landsat TM is typically the sensor of choice for BARC mapping, therefore Landsat 8 with its spectrally compatible OLI sensor is very important to the BAER community; however however other imaging platforms such as SPOT, ASTER, MODIS, VIIRS and multi-spectral aerial imagery can be used 
as well. For large fires, resources are prioritized to create BARC maps as quickly as possible so that BAER teams can begin assessing the burn area and, if needed, begin prioritizing treatments.

\subsection{The Water Erosion Prediction Project (WEPP)}

The online database currently provides comprehensive support for The Water Erosion Prediction Project (WEPP) Model. WEPP is a physically-based soil erosion model developed by an interagency team of scientists (Laflen et al. 1997). The surface hydrology component of WEPP utilizes climate, topography, soil, and vegetation parameters to predict plant growth, residue decomposition and soil water balance on a daily time step, and infiltration, runoff, and erosion on a storm-by-storm basis. WEPP then can provide runoff, erosion and sediment delivery by event, month, year, or average annual values for time periods ranging from 25 to 100 years, for either an individual hillslope or a watershed made up of many hillslopes and channels.

WEPP technology includes two versions, a hillslope version to estimate the distribution of erosion on a hillslope, and a watershed version that links hillslopes with channels and instream structures to estimate sediment delivery from small watersheds (under about 5 square $\mathrm{km}$ ). A Windows interface is available for both the watershed and hillslope versions of WEPP. Additionally, Forest Service scientists have developed user-friendly online interfaces for the hillslope version to model forest hillslopes, road segments, and hillslopes (Elliot 2006; Elliot et al. 1999; Robichaud et al. 2007a) following wildfire. The two main hillslope tools available for post-fire analysis are Disturbed WEPP, which predicts average annual surface runoff and erosion values, and the Erosion Risk Management Tool (ERMiT) that predicts the probability associated with the sediment delivery from a single runoff event (Elliot 2006, Robichaud et al. 2007a). These two interfaces link land cover to both vegetation properties and soil properties, so users need only select the land cover and a soil texture, and the interfaces select the correct soil and land cover files for a given run. Disturbed WEPP has land cover for mature and young forests, shrubs, good and poor grass communities, and low and high severity fires. ERMiT has databases for unburned, low, moderate and high severity fires on forests and rangelands.

The watershed version of WEPP is best run using GIS tools. Renschler (2003) developed the most commonly used GIS tool for ArcGIS 8.x, 9.x, 10.1, and 10.2 called "GeoWEPP" GeoWEPP uses the topographic analysis software, TOPAZ (Garbrecht and Martz 1999), to delineate watersheds and create the slope files needed to run WEPP. Typically, the same soil and vegetation files are used in the online Disturbed WEPP interface, the Windows interfaces, and the GIS tools.

Because of difficulties experienced by users in developing spatially distributed input files for GeoWEPP, an interagency team of scientists have recently released an online GIS watershed tool specifically developed for forest conditions including wildfire (Frankenberger et al. 2011). This interface does not require any downloading or pre-processing of topographic, soils, or land cover databases that were necessary for running GeoWEPP. In its current form, however, saving the outputs from a run, or combining multiple runs for a large fire can be awkward. It can only access soils that are part of the
NRCS SSURGO soils database, and SSURGO coverage is incomplete, particularly in remote forest watersheds.

\section{POST-FIRE EROSION DATABASE}

Our online database is being designed so that it can be used by both GeoWEPP and the online GIS WEPP tool. We also have plans to support additional models by providing flexibility in the format of the model inputs and we are looking into other commonly used models and their data needs. For this and other purposes, we are developing an open source web-based application programming interface (API), which will allow a remote computer to automatically download our spatial WEPP data products.

Spatial coverage of the online database is expanding. Soil, land cover, and elevation data along with burn severity for historical fires in Colorado are now online and available (http://geodjango.mtri.org/geowepp/). Users can either upload a new soil burn severity map into the database or select a historical fire. Soil coverage for California is nearly complete and may soon be complete for Idaho pending further collaboration. Once the soil burn severity map is in the online database it can be combined with land cover and soil datasets on demand in order to generate the spatial model inputs needed for hydrological modeling of burn scars. Model inputs can be created to represent the fire area both in its burned and unburned state. Users download three spatial layers: soils, land cover, and a digital elevation model (DEM) that have been coregistered and projected specifically for GeoWEPP or similar modeling efforts (Figs. 2,3,4). The soil data are based on the SSURGO or STATSGO NRCS soil databases (Soil Survey Staff, 2011; USDA, 1991); the DEM is from the U.S. Geological Survey (USGS) (Gesch et al., 2002; Gesch, 2007), and land cover is derived from LANDFIRE existing vegetation type data (Rollins, 2009; LANDFIRE, 2010).

Estimated runoff amounts, peak flows, upland erosion rates, and sediment delivery are used to improve decision-making activities related to post-fire risk assessment and rehabilitation treatment selection (Fig. 5). The new website and datasets deliver all the spatial inputs and parameter files needed for spatial WEPP (Water Erosion Prediction Project) models in mere seconds; previously, assembling and formatting this type of data would have taken at least several hours if not days. We are actively expanding our database to include the lower 48 states and we are seeking other post-fire erosion models to support; we currently have plans to create datasets for a postfire debris flow model and a dry ravel model.

\subsection{Spatial data layers}

Historical burn severity maps are from the Monitoring Trends in Burn Severity project (MTBS). MTBS is a partnership between the USGS and the USDA Forest Service Remote Sensing Application Center to map burn severity and fire perimeters using the dNBR algorithm used to create BARC maps for BAER Teams. These maps are not typically adjusted for post-fire soil conditions; therefore modellers should use soil burn severity maps if they are available. Fires occurring between 1984 and 2010 in Western US States greater than 1000 acres (400 ha) are included in the database. Data are freely available online (Monitoring Trends in Burn Severity, 2009). 
DEM data from the USGS Seamless Data Warehouse serves as the base layer. The National Elevation Dataset has 30-m Digital Elevation Model (DEM) data available for the entire U.S. with even higher resolution $(10 \mathrm{~m})$ available for most of the country (Gesch et al., 2002; Gesch, 2007). Soils and land cover data are projected to align with the DEM.

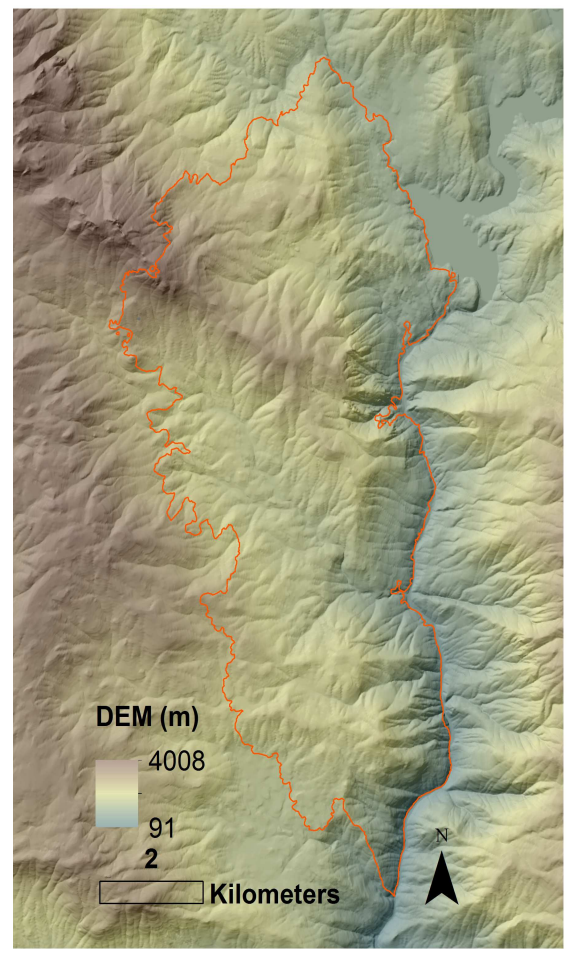

Figure 2. Example 30m DEM downloaded after the French Fire soil burn severity map was uploaded into the database.

For land cover data we initially planned to use the National Land Cover Dataset, but on collaborative projects where fire spread modeling was involved, the modellers recommended that that we use the Existing Vegetation Type (EVT) data from the LANDFIRE project (LANDFIRE, 2010). Therefore we reclassified the EVT cover types into Disturbed WEPP land cover categories. When an uploaded burn severity map is used, it is combined with vegetation to create a burned land cover map on-demand. This map is then reclassified into a soil burn severity map. This step is important as grasses and shrub lands do not have enough fuel to create high-severity impacts on soils and clay-textured soils seldom become water-repellent.

The necessary soil input layers are being derived from both SSURGO and STATSGO datasets. SSURGO data consists of the most detailed soil maps created by the Natural Resources Conservation Service (NRCS), but does contain some data gaps (Miller and White, 1998; Soil Survey Staff, 2011). To fill in gaps we are using the STATSGO (STATe Soil GeOgraphic) database which has complete coverage and is a seamless layer derived from soil surveys conducted by the U.S. Department of Agriculture (USDA, 1991). The STATSGO database does not have as fine a resolution in cover as the SSURGO database but this is not a great concern because in post fire modeling, the erosion potential of the soil is more a function of fire severity than it is of other soil properties (Elliot, 2013). Thus, when soils are impacted by fire, soil parameters are adjusted based on either unburned (forest or grass), low or high severity soil impacts.

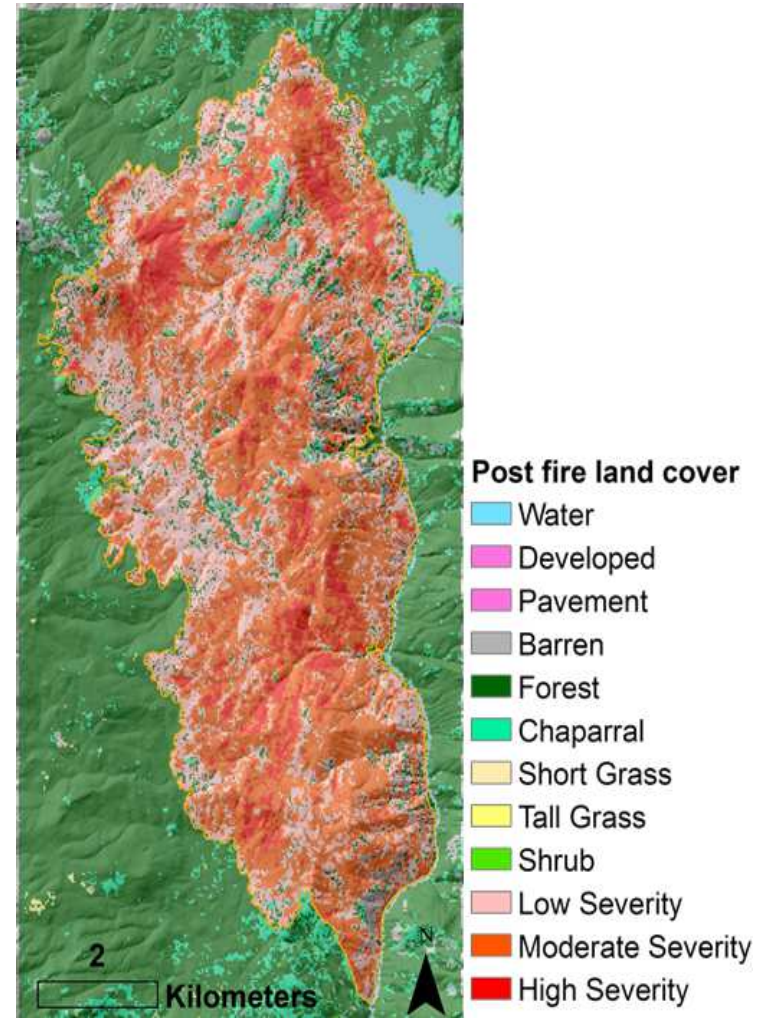

Figure 3. Example post-fire land cover map generated by the database for the French Fire.

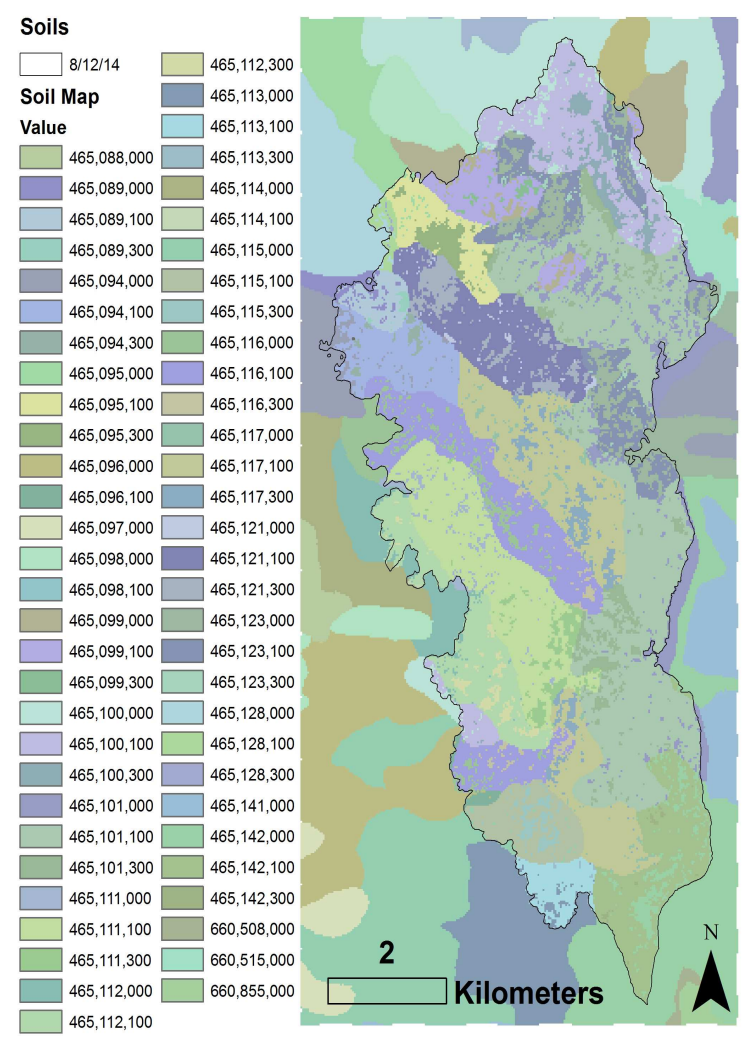

Figure 4. A soils map generated by the database depicting soil files modified by the burned French Fire land cover layer. To facilitate modeling the WEPP soil parameter and linkage files are also provided by the online database. 


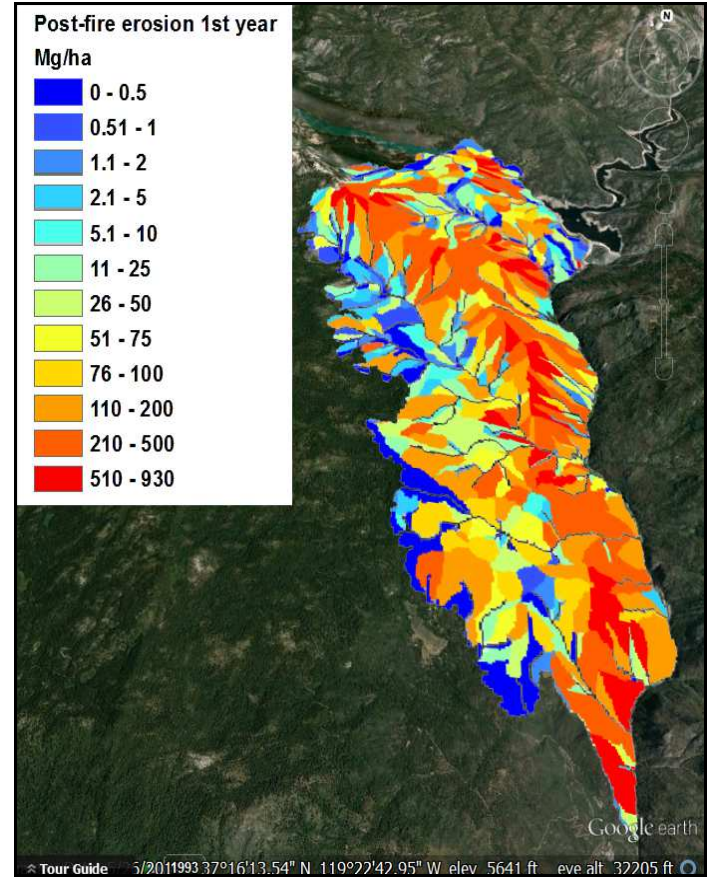

Figure 5. Post-fire hillslope erosion predictions for the French fire displayed in Google Earth.

\subsection{Database}

The spatial data we are developing is stored in PostGIS, a spatial database tool that extends the popular open-source database management system PostgreSQL, providing enterprise-level spatial functionality and expert community support at no cost. Furthermore, the PostGIS extension is stable, robust, and relatively simple to use. Most of the transformations of the DEM, soil, and land cover datasets necessary for use in spatial WEPP models are performed directly in the database at the time the user makes a request including spatial filtering, intersection and clipping, reclassification and raster addition. The PostGIS database produces DEM subsets and burned and unburned soil and land cover layers as rasters on-demand (on the order of 5-10 seconds over a broadband connection) for small fires (less than $20 \mathrm{~km}^{2}$ or 2,000 ha). Larger fires incur a larger wait time, however, compared to previous methods (manual preparation in a GIS), our approach is faster by several orders of magnitude.

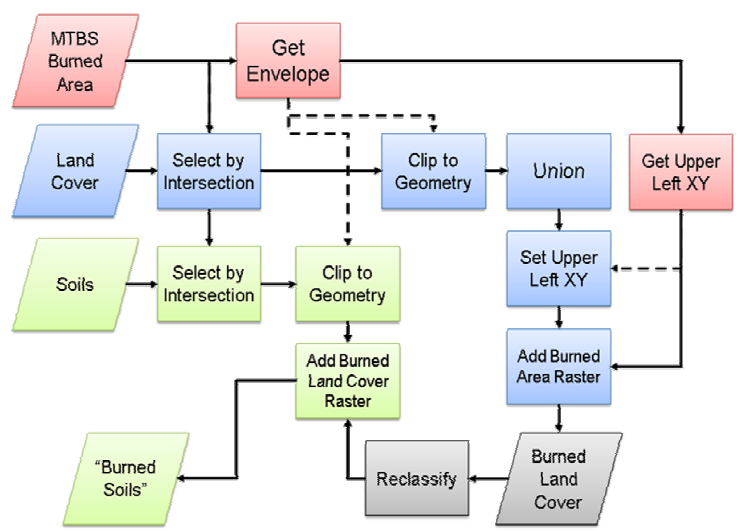

Figure 6. Example geo-processing workflow for the soils layer. Note that both the land cover and the soil properties are needed to develop the "burned soils" layer.

\section{DISCUSSION AND CONCLUSION}

The methodology used to rapidly combine soil burn severity maps with land cover and soils data for post-fire erosion modeling has been clearly demonstrated with case studies from two recent wildfires. The first wildfire is the 2011 Rock House fire that burned 127,500 ha (315,000 acres) in Presidio and Jeff Davis Counties, Texas. This wildfire impacted a small national historical site - Fort Davis, which is located in a small watershed called Hospital Canyon (217 ha; 536 acres). Even though the area that needed to be modelled was small, the time needed to reformat soil and vegetation data for modeling in GeoWEPP meant that predictions could not be completed in a timely fashion for the National Park Service BAER team. In 2012 when the High Park fire burned 35,300 ha (87,200 acres) in Larimer County, Colorado the spatial soil, land cover and DEM layers were already prepared along with a methodology for rapidly merging satellite-derived burn severity maps with the soil and vegetation data. The entire burn scar for the 2012 High Park fire was modeled in GeoWEPP in less than three days allowing the predictions to be available for operational use by the BAER team. These case studies clearly demonstrate the efficacy of preparing both the tools and datasets before they are needed.

Using our online tools and datasets we were able to support Forest Service BAER Teams on four fires that burned in 2014 in California (the French, Happy Camp, Silverado and King fires). The French (5,600 ha; 13,800 acres) and Silverado (390 ha; 968 acres) fires were relatively small; therefore predictions of post-fire erosion and runoff could be generated in GeoWEPP within just a few hours of receiving the soil burn severity maps. The larger King (39,500 ha; 97,700 acres) and Happy Camp (54,200 ha; 134,000 acres) fires both required one to two days to complete one modeling scenario. The BAER Team on the King fire wanted several modeling scenarios including predictions of average first year post-fire erosion (Fig. 7) and post-fire erosion from a single storm event. Having the datasets available rapidly means there is more time for BAER teams to model the effects of proposed remediation treatments. On both the King and Silverado fires multiple modeling runs were carried out to estimate impacts of proposed remediation treatments.

Assembling the data needed to run spatially explicit erosion models can be a daunting task even without time constraints, therefore preparing the required input data ahead of time makes sense. Work will be ongoing in the next two years to expand the database to cover the lower 48 states, once completed the database will be transferred to our federal partners. Our vision for this project is that advanced GIS surface erosion and mass failure prediction tools will be readily available for post-fire analysis using spatial information from a single online site. 


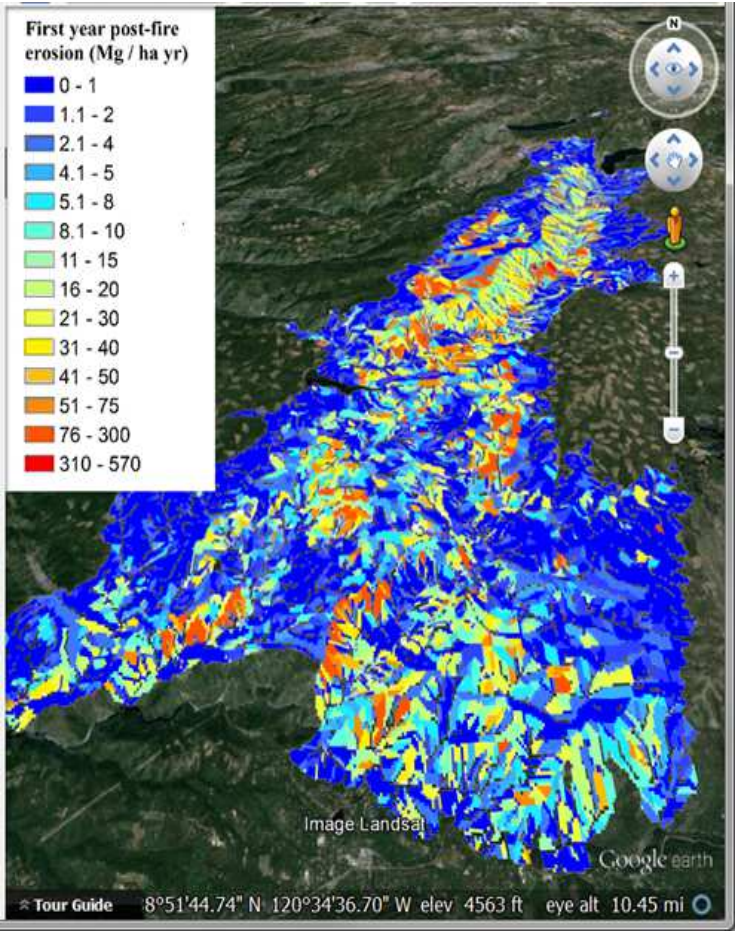

Figure 7. Post-fire hillslope erosion predictions for the King fire displayed in Google Earth.

\section{ACKNOWLEDGEMENTS}

We would like to acknowledge the NASA Applied Sciences Program for Wildfires for their support in developing tools and datasets to be used in modeling post-fire erosion and runoff. The authors are also grateful to the Forest Service BAER resource managers, and researchers who are testing our products and providing feedback.

\section{REFERENCES}

Agnew, W., R.E. Labn, and M.V. Harding, 1997. Buffalo Creek, Colorado, Fire and Flood of 1996. Land and Water 41, pp. 27-29.

Benavides-Solorio, J., MacDonald L.H., 2005. Measurement and prediction of post-fire erosion at the hillslope scale, Colorado Front Range. International Journal of Wildland Fire 14, pp. 1-18.

Bobbe T., Finco M.V., Quayle B., Lannom K., Sohlberg R., Parsons A., 2001. Field measurements for the training and validation of burn severity maps from spaceborne, remotely sensed imagery. Joint Fire Science Program. (Boise, ID) http://www.fs.fed.us/eng/rsac/baer/final_report_01B-2-1-01.pdf

Cannon S.H., Gartner J.E., Rupert M.G., Michaer J.A., Rea A.H., Parrett C., 2010. Predicing the probability and volume of postwildfire debris flows in the intermountain western United States. Geological Society of America Bulletin 122(1-2) 127144.

Debano L.F., 2000. The role of fire and soil heating on water repellency in wildland environments: a review. Journal of Hydrology 231-232 (2000) 195-206.
Elliot, W.J., 2013. Erosion processes and prediction with WEPP technology in forests in the Northwestern U.S. Trans. ASABE56(2): 563-579.

Elliot, W.J., Hall, D.E., and Scheele, D.L., 1999. Forest Sercice Interfaces for the Water Erosion Predicction Project Computer Model. United States Department of Agriculture Forest Service. http://forest.moscowfsl.wsu.edu/fswepp/

Elliot W., Hyde K., MacDonald L., and McKean J., 2010. Tools for analysis Chapter 13. IN Elliot WJ, Miller IS, and Audin L. eds. Cumulative Watershed Effects of Fuel Management in the Western United States. Gen. Tech. Rep. RMRS-GTR-231. Fort Collins, CO: U.S. Department of Agriculture, Forest Service, Rocky Mountain Research Station. 247-277.

Elliot, W. J., I. S. Miller and B. D Glaza, 2006. Using WEPP Technology to Predict Erosion and Runoff Following Wildfire. Presented at the ASAE Annual International Meeting, Jul 9-12, Portland, OR. Paper No. 068011. St. Joseph, MI: ASAE. 12p.

Frankenberger, J.R., S. Dun, D.C. Flanagan, J.Q. Wu and W.J. Elliot, 2011. Development of a GIS interface for WEPP model application to Great Lakes forested watersheds, Paper No. 11139. Presented at the International Symposium on Erosion and Landscape Evolution, 18-21 September, 2011, Anchorage, AL. St. Joseph, MI: Am. Soc. Ag \& Bio Engrs. 8

Garbrecht J, Martz LW, 1999 TOPAZ: an automated digital landscape analysis tool for topographic evaluation, drainage identification, watershed segmentation and subcatchment parameterization. USDA Agricultural Research Service Publication No. GRL 99-1. (El Reno, Oklahoma)

Gesch, D.B., 2007. The National Elevation Dataset, in Maune D ed., Digital Elevation Model Technologies and Applications: The DEM Users' Manual, 2nd Edition: Bethesda, Maryland, American Society for Photogrammetry and Remote Sensing, p. 99-118.

Gesch, D., Oimoen, M., Greenlee, S., Nelson, C., Steuck, M., and Tyler, D., 2002. The National Elevation Dataset: Photogrammetric Engineering and Remote Sensing, 68(1), pp. 5-11.

Key, C. and N. Benson, 2006. Landscape Assessment (LA) In: Lutes, Duncan C.; Keane, Robert E.; Caratti, John F.; Key, Carl H.; Benson, Nathan C.; Sutherland, Steve; Gangi, Larry J. 2006. FIREMON: Fire effects monitoring and inventory system. Gen. Tech. Rep. RMRS-GTR-164-CD. Fort Collins, CO: U.S. Department of Agriculture, Forest Service, Rocky Mountain Research Station. pp. LA-1-55.

Laflen, J. M., Elliot, W. J.; Flanagan, D. C.; Meyer, C. R.; Nearing, M. A., 1997. WEPP--Predicting water erosion using a process-based model. Journal of Soil and Water Conservation. 52(2), pp. 96-102.

Lambe, T.W. and R. V. Whitman, 1969. Soil Mechanics. John Wiley \& Sons, New York. 553 pp.

LANDFIRE: LANDFIRE 1.1.0 Existing Vegetation Type and Biophysical Settings layers. U.S. Department of the Interior, Geological Survey. [Online]. Available:

http://landfire.cr.usgs.gov/viewer/ [2010, October 28]. 
Miller, D.A. and R.A. White, 1998. A Conterminous United States Multi-Layer Soil Characteristics Data Set for Regional Climate and Hydrology Modeling. Earth Interactions, 2. [Available on-line at http://EarthInteractions.org]

Monitoring Trends in Burn Severity, 2009. United States Department of Agriculture Forestry Service/U.S. Geological Survey. http://forest.moscowfsl.wsu.edu/fswepp/

Moody J.A., Martin D.A., 2001. Hydrologic and sedimentation response of two burned watersheds in Colorado. U.S. Geological Survey Water Resources Investigative Report 014122. (Denver, Colorado)

Parsons A., Robichaud P.R., Lewis S.A., Napper C., Clark J. 2010. Field guid for mapping post-fire soil burn severity. Gen. Tech. Rep. RMRS-GTR-243. Fort Collins, CO: U.S. Department of Agriculture, Forest Service, Rocky Mountain Research Station. 49 p.

Pietraszek, J., 2006. 'Controls on post-fire erosion at the hillslope scale, Colorado Front Range.' M.S. thesis, Colorado State University (Fort Collins, Colorado)

Reid L.M., 2010. Cumulative effects of fuel treatments on channel erosion and mass wasting. IN Elliot WJ, Miller IS, and Audin L. eds. Cumulative Watershed Effects of Fuel Management in the Western United States. Gen. Tech. Rep. RMRS-GTR-231. Fort Collins, CO: U.S. Department of Agriculture, Forest Service, Rocky Mountain Research Station. 101-125.

Renard K.G., Foster G.R., Weesies G.A., McCool D.K., Yoder D.C., 1997. 'Predicting soil erosion by water: a guide to conservation planning with the Revised Universal Soil Loss Equation (RUSLE).' USDA Agriculture Handbook no. 703. (Washington, DC)

Renschler, C.S., 2003. Designing geo-spatial interfaces to scale process models: the GeoWEPP approach. Hydrological Processes 17, 1005-1017.

Robichaud P.R., Brown R.E., 1999. Rev. 2000 'What happened after the smoke cleared: onsite erosion rates after a wildfire in eastern Oregon.' Proc. Annual Summer Specialty Conference (Track 2: Wildland hydrology), pp. 419-426. (American Water Resources Association: Middleburg, Virginia)

Robichaud, P.R., 2000. Fire effects on infiltration rates after prescribed fire in Northern Rocky Mountain forests, USA. Journal of Hydrology 231-232, 220-229.

Robichaud P.R., Elliot W.J., Pierson F., Hall D.E. Moffet C.A., 2007a, Predicting postfire erosion and mitigation effectiveness with a web-based probabilistic erosion model. Catena 71: 229241.

Robichaud P.R., Lewis S.A., Laes D.Y.M., Hudak A.T., Kodaly R.F., Zamudio J.A. 2007b Post-fire soil burn severity mapping with hyperspectral image unmixing. Remote Sensing of Environment 108(4), 467-480.

doi:10.1016/J.RSE.2006.11.027

Rollins, M.G., 2009. LANDFIRE: a nationally consistent vegetation, wildland fire, and fuel assessment. International Journal of Wildland Fire 18, 235-249.
RSAC, 2011. Burned Area Emergency Response (BAER) Imagery Support http://www.fs.fed.us/eng/rsac/baer/ [Verified 12 December 2011]

Soil Survey Staff, Natural Resources Conservation Service, United States Department of Agriculture. Soil Survey Geographic (SSURGO) Database for [Survey Area, State]. Available online at http://soildatamart.nrcs.usda.gov. [Verified 12 December 2011].

USDA, 1991. 'State soil geographic (STATSGO) data base data use information.' U.S. Department of Agriculture Miscellaneous Publication 1492. (Washington, D.C.) 